\title{
Consumers Preferences Analysis Toward International Marketing Strategy for Salmon from Japan
}

\author{
Masashi Mochizuki ${ }^{1}$, Taro Oishi ${ }^{1}$, Yasuyuki Miyakoshi ${ }^{2} \&$ Nobuyuki Yagi $^{3}$ \\ ${ }^{1}$ Fukuoka Institute of Technology, Japan \\ ${ }^{2}$ Hokkaido Research Organization, Salmon and Freshwater Fisheries Research Institute, Japan \\ ${ }^{3}$ The University of Tokyo, Japan
}

Correspondence: Masashi Mochizuki, Department of Socio-Environmental Studies, Faculty of Socio-Environmental Studies, Fukuoka Institute of Technology, 3-30-1 Wajiro-higashi, Higashi-ku, Fukuoka, 811-0295 Japan. Tel: 81-92-606-6295

Received: August 10, 2018

Accepted: September 9, 2018 Online Published: November 24, 2018

doi:10.5539/ijms.v10n4p1

URL: https://doi.org/10.5539/ijms.v10n4p1

\begin{abstract}
In this paper, we construct an international marketing strategy aimed at expanding salmon exports from Hokkaido, Japan. We conduct online surveys with consumers from the United Kingdom (UK), Singapore, and South Korea, which are among the priority countries / regions in the "Hokkaido food export expansion strategy." We carry out a binomial logistic regression analysis using the factors that determine consumers' food preferences and how consumers differentiate between producing countries. As a result, we find that the factors that increase the probability of consuming salmon include "consumers believing that a country's fish is wild-caught," "consumers believing that a country's fishing is sustainable," "consumers being young" (the UK and South Korea only), "consumers having high-frequency seafood consumption " (the UK only), and "consumers having a high income" (the UK only). We also find that the UK does not differentiate between foreign salmon-exporting countries, while in Singapore, Japan's salmon is valued higher than fish from countries such as Chile, Russia, and Canada. In South Korea, on the other hand, Norway, the United States (Alaska), and Canada ranked the highest, while Japan ranked the lowest.
\end{abstract}

Keywords: consumer preference, international marketing, salmon, sustainable fishing, wild-caught

\section{Introduction}

Chum salmon Oncorhynchus keta is one of the important commercial fish species in northern Japan. In Japan, chum salmon fisheries have been supported by hatchery programs; i.e. juveniles reared in hatcheries are released into the wild and returning chum salmon are caught in coastal commercial fisheries (Miyakoshi et al., 2013). Although other salmon species (pink salmon $O$. gorbuscha and masu salmon $O$. masou) are also caught, majority of the Japanese salmon catches are chum salmon. Since the 1980s, prices of chum salmon in Japan local fish markets fell sharply due to an oversupply caused by domestic salmon catch increasing rapidly in line with increasing farmed salmon (including coho salmon $O$. kisutch, rainbow trout $O$. mykiss, and Atlantic salmon Salmo salar) imports from Norway and Chile.(Note 1) For this reason, in 1994 companies began the full-scale export of frozen salmon from Hokkaido (the center of Japan's salmon fisheries) (Note 2) to China for processed foods use, in order to stabilize Hokkaido's salmon market prices (Shimizu, 2007; Yamao, 2013) (Note 3). Most frozen Japanese salmon exported to China was processed and then re-exported to other countries. Since salmon is not a big part of the Chinese food culture, this salmon was not intended for domestic Chinese consumption (Yao, 2011). Furthermore, when Japan started exporting salmon to China, the exports mainly consisted of low grades of salmon not being sold in Japan. However, because China has become a worldwide processing hub in recent years, with exports to places such as the European Union (EU) and North America, Japan now also exports relatively high grades as well (Yamao, 2013).

Since it is expected that the international seafood market will expand further in the future, in 2013 the Japanese government (the Ministry of Agriculture, Forestry, and Fisheries) formulated an "export strategy to differentiate agriculture, forestry, and fishery products by country and commodity" in an attempt to devise a method to expand exports of these types of products (Note 4). To realize this strategy, the "Hokkaido food export expansion 
strategy"(Note 5) was formulated in Hokkaido in 2016, and chum salmon was set as one of the priority items, with China, Thailand, Vietnam, Singapore, Hong Kong, Taiwan, South Korea, the EU, and the United States being the priority countries / regions where to expand exports.

However, when looking at trends in the salmon market around the world, while overall demand is growing (FAO, 2016), Norwegian and Chilean farmed salmon occupy the majority of the global salmon market. Furthermore, America (Alaska), being one of the largest salmon fisheries, acquired the sustainable fisheries Marine Stewardship Council (MSC) ecolabel for their wild salmon catch, and began exporting to the Chinese market (Nagata et al., 2012). Therefore, competition between Japan and other salmon-producing countries is heating up.

Therefore, in order to construct an international marketing strategy for salmon exports expansion from Hokkaido in this paper, we set out to clarify overseas consumers' salmon food preferences, focusing on the fact that most salmon from Hokkaido is caught in coastal waters (Note 6). When identifying preference factors, besides demographic attributes such as gender, age, and income, as well as seafood consumption frequency, we concentrate on the presence or absence of (i) consumers' differentiation on the country of origin, (ii) consumers' recognition of regions where salmon is wild-caught, and (iii) consumers' recognition of sustainable fishing. We selected the UK, Singapore, and South Korea as the targets for analysis, as they were among the priority countries / regions of the "Hokkaido food export expansion strategy."

\section{Data Description and Analysis}

\subsection{Data Description}

To collect data for the analysis, we conducted an online consumer survey between January 11 and 19, 2017 in the UK and Singapore, and January 23 and 31, 2017 in South Korea. The survey's target group sampling method utilized monitors registered with an online survey company and found respondents (600 people in each country) representing the country's population composition ratios with respect to gender and age (5 age groups - 20s, 30s, 40s, 50s, and 60s) (Table 1) (Note 7).

Table 2 displays the survey questions, variable names, and variables definitions (Note 8). Besides questions on demographic attributes such as "gender (Q1)," "age (Q2)," and "educational level (Q3)," we also asked about "income (Q4)," "frequency of seafood consumption (Q5)," "whether they differentiate between countries of origin (Q6)," "consumers' impressions if most salmon from each country is wild or farmed (Q7)," "consumers' impressions if the salmon from each country is caught in a sustainable manner (Q8)," and "whether consumers would like to eat salmon from specific countries (Q9)." The method of responding to the age question was an input form. For all other questions, respondents could make one choice from multiple options. Respondents' answers to questions 7 through 9 represented their assumptions about salmon from Japan, Norway, Chile, the US (Alaska), Russia, the UK, and Canada. Please note that we interpreted the answers to Q6 "not concerned about the country of origin" to mean that the consumers had no country-specific preferences for salmon, so only those who answered Q6 in the affirmative (those who are concerned about the country of origin) were asked Q9.

Table 1. Data description by age and gender (number of people). Numbers in brackets represent percentage out of the total

\begin{tabular}{|c|c|c|c|c|c|c|c|c|c|c|c|c|}
\hline \multirow{2}{*}{ Age demographic } & \multicolumn{4}{|c|}{ UK } & \multicolumn{4}{|c|}{ Singapore } & \multicolumn{4}{|c|}{ South Korea } \\
\hline & \multicolumn{2}{|c|}{ Male } & \multicolumn{2}{|c|}{ Female } & \multicolumn{2}{|c|}{ Male } & \multicolumn{2}{|c|}{ Female } & \multicolumn{2}{|c|}{ Male } & \multicolumn{2}{|c|}{ Female } \\
\hline $20-29$ & 64 & {$[11]$} & 62 & {$[10]$} & 58 & {$[10]$} & 58 & {$[10]$} & 60 & [10] & 53 & [9] \\
\hline $30-39$ & 60 & {$[10]$} & 62 & {$[10]$} & 60 & {$[10]$} & 66 & {$[11]$} & 66 & [11] & 62 & [10] \\
\hline $40-49$ & 64 & [11] & 64 & {$[11]$} & 64 & {$[11]$} & 68 & {$[11]$} & 72 & [12] & 70 & [12] \\
\hline $50-59$ & 60 & [10] & 62 & {$[10]$} & 66 & [11] & 84 & [14] & 68 & [11] & 67 & [11] \\
\hline $60-69$ & 50 & {$[8]$} & 52 & [9] & 46 & {$[8]$} & 30 & {$[5]$} & 40 & {$[7]$} & 42 & [7] \\
\hline Total & 298 & {$[50]$} & 302 & {$[50]$} & 294 & [49] & 306 & [51] & 306 & [51] & 294 & [49] \\
\hline
\end{tabular}

\subsection{Method for Analysis}

We employed a binomial logistic regression model using a logit model. Logit models are commonly used in research fields related to consumer behavior. Previous research on consumers' seafood products preferences has been done by researchers such as Dellenbarger et al. (1992), Herrmann et al. (1993), Nayga and Capps (1995), Bose and Brown (2000), Al-Mazrooei et al. (2003), and Musaba and Namukwambi (2011). These previous studies analyzed factors affecting consumers' purchasing behaviors, such as regions where consumers live and shop, and differences in purchasing patterns (Note 9). However, as the global trade of seafood products has 
grown in recent years, understanding consumer behavior in export-destination countries has become important when considering seafood products as international commodities. This paper focuses on analyzing consumer behavior with respect to imported seafood products, using a binomial logistic regression model targeting salmon, which is an international commodity.

The paper's specific analytical model is presented below. The probability " $p$ " that a respondent wants to eat salmon $(\mathrm{EAT}=1)$ is the dependent variable, and the variables described in Table 2_"gender (GENDER)," "age (AGE)," "education (EDUCATION)," "income (INCOME)," "seafood consumption frequency (CONFREQ)," "wild catch (WILD)" (the impression consumers have regarding the wild catch in the countries of origin), "sustainable fisheries (SUSTAINABLE)" (the impression consumers have regarding the sustainability of salmon fisheries in the countries of origin), and the "country-of-origin dummy variable (D)" (indicating the country where salmon is caught) — are the explanatory variables. We estimate the following binomial logistic regression model:

$$
\begin{gathered}
p=\exp (y) /(1+\exp (y)) \\
y=\beta_{0}+\beta_{1} \text { GENDER }+\beta_{2} A G E+\beta_{3} \text { EDUCATION }+\beta_{4} I N C O M E \\
+\beta_{5} \text { CONFREQ }+\beta_{6} \text { WILD }+\beta_{7} \text { SUSTAINABLE }+\sum_{i=8}^{13} \beta_{i} D_{i}
\end{gathered}
$$

Here, $\{\beta 0, \beta 1, \ldots, \beta 13\}$ are the coefficient estimated in the model. $\mathrm{D}$ is a dummy variable for salmon producing countries (D8 = 1 when Norway is chosen, D9 = 1 for Chile, D10 = 1 for the United States (Alaska), D11 = 1 for Russia, D12 = 1 for the UK, and D13 = 1 for Canada).

Please note that the reason why we add a country-of-origin dummy to the set of explanatory variables in this paper is to clarify whether or not consumers differentiate between countries of origin. This allows us to verify whether Japan has brand equity as a salmon-producing country in the export destination countries. The country-of-origin's image is important in branding. A country-of-origin's image has been shown to have a significant positive effect on brand equity and the elements that constitute brand equity (Mohd Yasin et al., 2007) (Note 10). In addition, since the government believes that a strong country brand can contribute to the country's sustainable development, the government is focusing on branding techniques that help to differentiate the country on the international stage, in order to increase its competitiveness against rival countries (Jaffe \& Nebenzahl, 2001; Kleppe \& Mossberg, 2006).

Since the country-of-origin dummy variable based on Japan is set, if the estimated country-of-origin dummy "odds ratio" is statistically significant, it implies that Japan's image as a salmon-producing country is differentiated from other countries. Also, the magnitude of the estimated odds ratio can be regarded as an indicator of how much brand equity Japan has compared to other salmon-producing countries. An odds ratio smaller than 1 means that Japan has less brand equity than other countries, and conversely, an odds ratio larger than 1 implies that Japan has more brand equity than other countries.

To address the problem of multicollinearity, before performing the binomial logistic regression analysis, the VIF (Variance Inflation Factor) statistic was calculated as an index of the correlation between explanatory variables. Multicollinearity may exist if VIF $\geqslant 5$ (Note 11 ). In cases where there was a possibility that multicollinearity exists, we dealt with it by removing one explanatory variable from the model. Since the assumption of uniform dispersion (heteroskedasticity) may not be satisfied in the binomial logistic regression model, we used "robust standard errors" which assume heterogeneous dispersion. The analysis in this paper was carried out using StataCorp's statistical analysis software Stata 13.1. 
Table 2. Survey questions, variable names, and variables descriptions

\begin{tabular}{lll}
\hline Variable name & & \multicolumn{1}{c}{ Question } \\
GENDER & Q1. & Please indicate your gender. \\
AGE & Q2. & Please enter your age. \\
EDUCATION & Q3. & Please indicate Your highest education level.
\end{tabular}

INCOME

Q4. Please indicate your household yearly income.
Q5. How often do you consume fish and other seafood?

CONCERNED

WILD

SUSTAINABLE

EAT
Globally, salmon is produced extensively in Norway, Chile, US(Alaska), Russia, Japan, UK, and Canada. When you eat any salmon products or dishes, do you have any concerns about its country of origin?

Q7. Which countries do you think have thriving production of wild or farmed salmon and trout? Please answer for each of the countries listed below. [Japan (Hokkaido), Norway, Chile, US(Alaska), Russia, UK, Canada]

Q8. What do you know about sustainability in the production of salmon and trout in different countries? Please choose one answer for each of the countries listed below. [Japan (Hokkaido), Norway, Chile, US(Alaska), Russia, UK, Canada]

Q9. If your answer to Q6 was "1. I am concerned about the country of origin," please answer the following question. When you eat any salmon products or dishes, do you want to eat salmon that has been produced by specific countries? Please answer once for each of the countries listed below. [Japan (Hokkaido), Norway, Chile, US(Alaska), Russia, UK, Canada]
Female $=0$, Male $=1$

Scale Explanation

20 - 69 years old

Primary or Junior high school or High school $=1$, Vocational school or Junior college $=2$, University (Bachelors or 4-year degree) or Graduate school $=3$

[UK]

Less than GBP 7,000 $=1$, GBP 7,000 - less than GBP 14,000 $=2$, GBP $14,000-$ less than GBP $21,000=3$, GBP21,000 less than GBP $28,000=4$, GBP 28,000 - less than GBP $35,000=5$, GBP $35,000-$ less than GBP $42,000=6$, GBP 42,000 - less than GBP $49,000=7$, GBP 49,000 - less than GBP $56,000=8$, GBP 56,000 - less than GBP $63,000=9$, GBP $63,000-$ less than GBP 70,000 $=10$, GBP 70,000 - less than GBP $80,000=11$, More than GBP $80,000=12$

[Singapore]

Less than SGD $12,500=1$, SGD 12,500 - less than SGD $25,000=2$, SGD $25,000-$ less than SGD $37,500=3$, SGD 37,500 - less than SGD 50,000 $=4$, SGD 50,000 - less than SGD $62,500=5$, SGD $62,500-$ less than SGD 75,000 $=6$, SGD 75,000 - less than SGD 87,500 = 7, SGD 87,500 - less than SGD $100,000=8$, SGD $100,000-$ less than SGD $112,500=9$, SGD $112,500-$ less than SGD $125,000=10$, SGD $125,000-$ less than SGD $150,000=11$, More than SGD $150,000=12$

[South Korea]

Less than KRW 10 million = 1, KRW 10 million - less than KRW 20 million $=2$, KRW 20 million - less than KRW 30 million $=3$, KRW 30 million - less than KRW 40 million $=4$, KRW 40 million - less than KRW 50 million $=5$, KRW 50 million - less than KRW 60 million = 6, KRW 60 million less than KRW 70 million $=7$, KRW 70 million - less than KRW 80 million $=8$, KRW 80 million - less than KRW 90 million $=9$, KRW 90 million - less than KRW 100 million = 10, KRW 100 million - less than KRW 120 million $=11$, More than KRW 120 million $=12$

Never $=1$, Less than once a year $=2, \mathrm{~A}$ few times a year $=3$, A few times a month $=4$, A few times a week $=5$, Almost everyday $=6$

I am not concerned about the country of origin $=0$, I am concerned about the country of origin $=1$

Farmed salmon and trout production is thriving $=0$, Wild salmon and trout production is thriving $=1$

Country does not have sustainable salmon and trout fisheries and aquaculture industries $=0$, Country has sustainable salmon and trout fisheries and aquaculture industries $=1$

Do not want to eat $=0$, Want to eat $=1$ 


\section{Results}

\subsection{Differentiation Between Salmon-Producing Countries}

Question 6 "When you eat any salmon products or dishes, do you have any concerns about its country of origin?" aims to grasp if consumers make a differentiation between countries of origin. 228 respondents (38\%) in the UK, $275(46 \%)$ in Singapore, and $308(51 \%)$ in South Korea "are concerned about the country of origin" (Fig. 1). Of those who responded that they "are concerned about the country of origin," $48 \%$ in the UK and Singapore, and $46 \%$ in South Korea were males. Although the proportion of women who answered similarly was somewhat larger across all countries, the difference was barely noticeable.

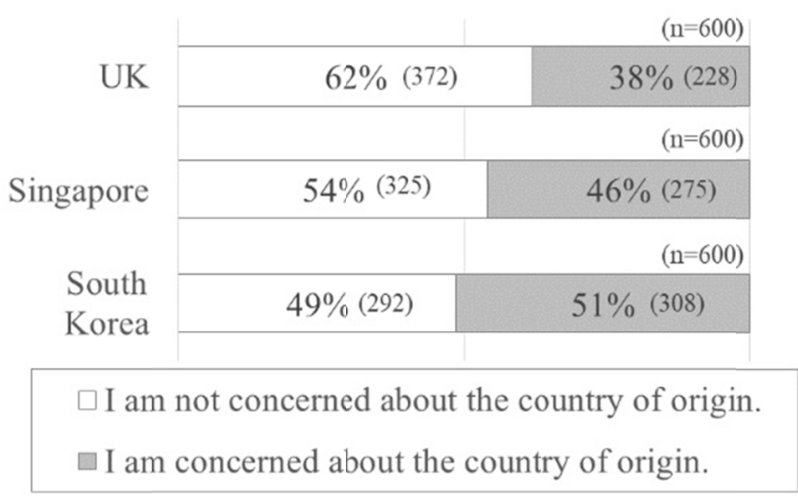

Figure 1. Summary of answers to Q6 (people who answered CONCERNED in Table 1)

\subsection{Binomial Logistic Regression Analysis}

To examine the possibility of multicollinearity between the explanatory variables, we use the VIF statistics. Since the VIF maximum value is 2.30 , we conclude that there is no multicollinearity between any of the explanatory variables (Table 3). Therefore, all of the variables shown in Equation (1) were used in the binomial logistic regression analysis.

Table 4 shows the results of the binomial logistic regression analysis assuming an uneven variance in the UK, Singapore, and South Korea.

Results for the UK were significant at the $1 \%$ confidence level for INCOME, WILD, and SUSTAINABLE, at the $5 \%$ confidence level for CONFREQ, and at the $10 \%$ confidence level for AGE, UK, and the constant term. The odds ratio was 0.967 for AGE, 1.319 for INCOME, 1.509 for CONFREQ, 10.249 for WILD, 9.625 for SUSTAINABLE, 5.595 for UK, and 0.044 for the constant term.

Results for Singapore were significant at the 1\% confidence level for WILD, SUSTAINABLE, CHILE, and RUSSIA, and at the $10 \%$ confidence level for CANADA. The odds ratios were 2.928 for WILD, 8.519 for SUSTAINABLE, 0.146 for CHILE, 0.137 for RUSSIA, and 0.292 for CANADA.

Results for South Korea were significant at the 1\% confidence level for WILD and all country of origin dummies, and at the $10 \%$ confidence level for AGE and SUSTAINABLE. The odds ratios were 0.975 for AGE, 4.171 for WILD, 1.986 for SUSTAINABLE, 90.226 for NORWAY, 5.648 for CHILE, 37.299 for US (ALASKA), 5.012 for RUSSIA, 6.083 for UK and 53.009 for CANADA. 
Table 3. VIF results

\begin{tabular}{lr}
\hline \multicolumn{1}{c}{ Variable } & VIF \\
\hline GENDER & 1.07 \\
AGE & 1.05 \\
EDUCATION & 1.14 \\
INCOME & 1.12 \\
CONFREQ & 1.07 \\
WILD & 1.11 \\
SUSTAINABLE & 1.12 \\
Country-of-Origin Dummy: Reference Category=Japan(Hokkaido) & \\
$\quad$ NORWAY & 2.30 \\
$\quad$ CHILE & 1.53 \\
$\quad$ US(ALASKA) & 2.08 \\
$\quad$ RUSSIA & 1.55 \\
$\quad$ UK & 1.30 \\
$\quad$ CANADA & 1.84 \\
\hline
\end{tabular}

Table 4. Binomial logistic regression analysis results assuming heterogeneous dispersion

\begin{tabular}{|c|c|c|c|c|c|c|c|c|c|c|c|c|}
\hline \multirow[b]{2}{*}{ Variable } & \multicolumn{4}{|c|}{ UK } & \multicolumn{4}{|c|}{ Singapore } & \multicolumn{4}{|c|}{ South Korea } \\
\hline & $\begin{array}{l}\text { Odds } \\
\text { Ratio } \\
\end{array}$ & $\begin{array}{c}\text { Robust } \\
\text { SE }\end{array}$ & $z$ & & $\begin{array}{l}\text { Odds } \\
\text { Ratio }\end{array}$ & $\begin{array}{c}\text { Robust } \\
\text { SE }\end{array}$ & $z$ & & $\begin{array}{l}\text { Odds } \\
\text { Ratio }\end{array}$ & $\begin{array}{c}\text { Robust } \\
\text { SE }\end{array}$ & $z$ & \\
\hline GENDER & 1.443 & 0.692 & 0.76 & & 1.439 & 0.526 & 0.99 & & 1.102 & 0.411 & 0.26 & \\
\hline AGE & 0.967 & 0.020 & -1.65 & $*$ & 0.984 & 0.016 & -0.99 & & 0.975 & 0.015 & -1.65 & $*$ \\
\hline EDUCATION & 1.010 & 0.318 & 0.03 & & 0.681 & 0.175 & -1.49 & & 1.072 & 0.305 & 0.25 & \\
\hline INCOME & 1.319 & 0.112 & 3.26 & $* * *$ & 1.103 & 0.067 & 1.61 & & 1.031 & 0.067 & 0.48 & \\
\hline CONFREQ & 1.509 & 0.286 & 2.17 & $* *$ & 1.024 & 0.275 & 0.09 & & 0.936 & 0.213 & -0.29 & \\
\hline WILD & 10.249 & 5.653 & 4.22 & $* * *$ & 2.928 & 1.127 & 2.79 & $* * *$ & 4.171 & 1.577 & 3.78 & $* * *$ \\
\hline SUSTAINABLE & 9.625 & 5.241 & 4.16 & $* * *$ & 8.519 & 3.552 & 5.14 & $* * *$ & 1.986 & 0.823 & 1.66 & $*$ \\
\hline \multicolumn{13}{|c|}{ Country-of-Origin Dummy: } \\
\hline NORWAY & 1.505 & 1.261 & 0.49 & & 0.688 & 0.507 & -0.51 & & 90.226 & 92.563 & 4.39 & $* * *$ \\
\hline CHILE & 0.637 & 0.467 & -0.62 & & 0.146 & 0.102 & -2.75 & $* * *$ & 5.648 & 2.787 & 3.51 & $* * *$ \\
\hline US(ALASKA) & 1.760 & 1.691 & 0.59 & & 0.863 & 0.648 & -0.2 & & 37.299 & 30.106 & 4.48 & $* * *$ \\
\hline RUSSIA & 0.331 & 0.253 & -1.45 & & 0.137 & 0.096 & -2.85 & $* * *$ & 5.012 & 2.635 & 3.07 & $* * *$ \\
\hline UK & 5.595 & 5.402 & 1.78 & $*$ & 0.343 & 0.241 & -1.52 & & 6.083 & 4.115 & 2.67 & $* * *$ \\
\hline CANADA & 2.148 & 1.589 & 1.03 & & 0.292 & 0.189 & -1.9 & $*$ & 53.009 & 54.905 & 3.83 & $* * *$ \\
\hline CONSTANT & 0.044 & 0.074 & -1.87 & $*$ & 8.958 & 15.652 & 1.25 & & 1.033 & 1.740 & 0.02 & \\
\hline Number of obs & & 340 & & & & 521 & & & & 587 & & \\
\hline Wald chi2(13) & & 74.62 & & & & 86.41 & & & & 92.57 & & \\
\hline Prob $>$ chi2 & & 0.000 & & & & 0.000 & & & & 0.000 & & \\
\hline Pseudo $R^{2}$ & & 0.512 & & & & 0.304 & & & & 0.369 & & \\
\hline Log pseudolikelihood & & -71.03 & & & & -105.05 & & & & -112.29 & & \\
\hline
\end{tabular}

Note. $* \mathrm{p}<0.05,{ }^{* *} \mathrm{p}<0.01,{ }^{* * *} \mathrm{p}<0.001$.

\section{Discussion and Conclusion}

In this paper, we construct an international marketing strategy to expand salmon exports from Japan (Hokkaido). We gathered data through online consumer surveys in the UK, Singapore, and South Korea, which are among the priority countries / areas of the "Hokkaido food export expansion strategy." We carried out a binomial logistic regression analysis on the determinants of consumers' differentiation between salmon-producing countries, as well as consumers' food preferences.

As a result, we found that around $40 \%$ of respondents in the UK and about $50 \%$ of the respondents in Singapore and South Korea are concerned about the country of origin when eating salmon products and cuisine, so half or nearly half of people differentiate between salmon-producing countries. Moreover, since there is no major difference in respondents' gender ratio in the "concerned" category, we surmised that there is no gender disparity when it comes to differentiating between salmon-producing countries.

From the results of the binomial logistic regression analysis, we were able to understand the following.

In the UK, "age," "income," and "seafood consumption frequency" are deciding factors. The younger consumer 
with a higher income and higher seafood consumption frequency has a higher probability of eating salmon. In addition, "wild catches" and "sustainable fishing" are also determinants. A higher proportion of consumers prefer eating salmon from countries where wild catches are perceived to be flourishing and where sustainable fishing is taking place than salmon from countries in which this is not the case. Regarding the "country-of-origin dummy variable," only the UK respondents favoring their own country was statistically significant. Since the odds ratio is larger than 1, UK consumers highly value domestic over foreign products, and we found out that all foreign brands had a similar level of brand equity.

In Singapore, "wild catches" and "sustainable fishing" are deciding factors, and a higher proportion of consumers prefer eating salmon from countries where wild catches are perceived to be flourishing and sustainable fishing is taking place than salmon from countries in which this is not the case. In addition, regarding the "country-of-origin dummy variable," CHILE, RUSSIA, and CANADA had statistically significant results. Since the odds ratio for each country is less than 1, we came to understand that for Singaporean consumers, Japan has higher brand equity as a salmon-producing region than Chile, Russia, and Canada.

"Age" is a determinant in South Korea and in the UK, and we found out that the younger someone is, the more likely they are to want to eat salmon. Also, as in the UK and Singapore, "wild catches" and "sustainable fishing" are also determinants, and we found that a higher proportion of consumers prefer eating salmon from countries where wild catches are perceived to be flourishing and sustainable fishing is taking place than salmon from countries in which this is not the case. In addition, statistically significant results were obtained for the "country-of-origin dummy variable" for all countries. In all cases the odds ratio was larger than 1, with exceedingly high odds ratios for NORWAY, ALASKA, and CANADA which were 90.226, 37.299 and 53.009, respectively. In other words, for South Korean consumers, Norway, the US (Alaska), and Canada have high brand equity as salmon-producing regions than other countries, while Hokkaido's assessment was low, with the lowest brand equity among all salmon-producing regions. We believe that the reason why Japan has a negative image as a salmon-producing region has to do with the import ban by the South Korean government on Japanese seafood products from places like the Fukushima Prefecture after the Fukushima Daiichi nuclear accident (Note 12), and its ensuing negative influence on Japan's reputation. Also, Norwegian salmon was valued the most, even though the country mostly relies on fish farms for its salmon. This seems to contradict South Koreans' desire to eat wild-caught salmon. This contradictory result is due to the fact that many Koreans have not yet come to realize that Norway is a country that is deeply into aquaculture (Note 13).

Based on our analysis and the above results, in order to expand salmon exports from Japan, we believe that (i) developing advertising campaigns that will help people recognize that Japan is a country where wild catches are thriving, and (ii) utilizing international certification systems, such as ecolabels to show that salmon is sustainably caught, will be effective measures to appeal to these three countries. Furthermore, we believe that (iii) sales strategies targeting young people will be effective with regards to the UK and South Korea. In addition, we believe that (iv) sales strategies targeting high-income groups, and (v) efforts to increase the frequency of seafood consumption will also be effective in the UK.

However, Japan's image as a salmon-producing country is low in South Korea, and because there is a big difference in brand equity between Japan and other salmon-producing countries, the barriers to entry into the South Korean market are high. We expect that export expansion in South Korea will be difficult, as previous studies have also suggested that barriers to entry are high. According to the survey conducted by Lee et al. (2017), there is a lingering high level of concern in South Korea regarding the risk associated with Japanese seafood following the Fukushima nuclear power plant accident; the majority responded that they would not purchase Japanese seafood even if radioactivity levels in the food were non-detectable. Furthermore, Lee et al. (2017) mentioned that since confidence in information providers, including government agencies, has a large influence on the risk perceptions of radioactive contamination of food as well as consumption behavior and policy directions, trust needs to be built between the provider and the recipient of the information. In other words, even if the Japanese government urged the South Korean government to restore confidence in Japanese seafood, it is thought that most consumers would not purchase Japanese seafood unless trust and information sharing can be successfully established between the government (information provider) and the public (information recipient) in South Korea. This means that the cost of entry into the South Korean market will be high, and it can be said that the charm of the export destination country is low.

Developing an image strategy for Japan regarding wild catches as proposed in (i) above also means improving the value-added of salmon from Japan separately from consumers' sensory qualities. According to Claret et al. (2016), who investigated the impact on consumer preferences of providing information about production methods (wild capture/aquaculture), consumers preferred wild fish in the informed condition. Moreover, Farmer 
et al. (2000) concluded that farmed salmon was at least as acceptable as wild salmon in terms of appearance, odor, flavor, texture, and aftertaste when blind tasted. These findings suggest that providing information about wild capture will improve its value to consumers separately from the sensory qualities. In other words, efforts toward (i) are expected to be useful for differentiating Japan's wild salmon and farmed salmon (e.g., Norwegian or Chilean salmon) in an aspect other than consumers' sensory qualities.

Utilizing international certifications, as in (ii) above, is also closely related to the results of Alfnes (2017), who showed that European consumers react positively to both store policies and regulations that ensure only sustainable seafood is sold in stores. This means that there is a possibility that the market for seafood that is not sustainable fishery may be narrowed in the future. Therefore, receiving international certification showing sustainable fishery will be an important marketing strategy for Japan's salmon to survive in the European market. Through case studies on seafood and palm oil, Berry and Weaver (2018) examined whether demand for certified sustainable products is having an effect on international trade, and concluded that there is evidence that certification may help producers grow and maintain their market share in developed countries (particularly in Europe). Therefore, efforts on (ii) are expected to contribute to expanding and maintaining the international market share of Japan's salmon.

Regarding points (iii) to (v), sales strategies to be considered include those that appeal to health-conscious people who care about the functional aspects of seafood (e.g., Hibbeln, 2002; Larsen et al., 2011), and sales promotional activities that further popularize seafood-based Japanese food. An important aspect of the Singapore market is that, because about $15 \%$ of Singapore's population is Muslim, Singapore is known to have an established halal market (El-Bassiouny, 2018). Halal certification, which proves that products are cooked and manufactured according to Islamic precepts, is important for foods consumed by Muslims. When Japan intends to export canned food and cooked foods using salmon to Singapore, Halal certification will be an important way to open up new markets.

Finally, we will describe the academic significance of this paper as well as some remaining challenges.

Some existing studies that analyze consumers' preferences in various countries for salmon imported from abroad include Herrmann et al. (1993), Rora et al. (2004), Green-Petersen et al. (2009), and Muhammad and Jones (2011). In these previous studies, consumers' preferences for imported salmon in various places such as Japan, North America, the European Community (EC), France, Iceland, Denmark, the Netherlands, and Ireland were analyzed. However, analysis of the three aforementioned countries that are important as Japan's marketing targets have not been done. Also, in Herrmann et al. (1993) and Green-Petersen et al. (2009), differences among salmon-producing countries were not taken into consideration, and in Rora et al. (2004) and Muhammad and Jones (2011), salmon-producing countries were taken into consideration, but Japan was not included as one of them. Therefore, no useful information was able to be obtained for international marketing of salmon caught in Japan. In addition, looking at the analysis results, Rora et al. (2004) who conducted a smoked salmon taste test for French consumers, said that "there were no significant preferences according to country of origin of the fish." On the other hand, Muhammad and Jones (2011), who analyzed the primary factor leading to salmon import demand using macro data from the United States, found that "import preferences are not homogeneous across exporting countries," so the results have been inconsistent. The academic significance of our research is that it adds new knowledge about consumers' food preferences in the UK, Singapore, and South Korea to the existing research, and clarifies whether consumers differentiate between major salmon-producing countries.

Since this paper focuses on export strategies at the national level by observing whether consumers in countries that are targeted for exports have a desire to eat salmon, our analysis did not take into account the quality of the salmon (body color, amount of fat, etc.) or differences in food preparation methods. However, an interview survey was carried out in March 2018 by the Singapore government's Food Diversification \& Supply Chain Department along with Japanese restaurants in Singapore, which was conducted as part of a research project influenced by this paper. The results showed that salmon's fat content and color, as well as differences between the preparation methods, have a large impact on salmon's value. Thus, understanding market needs, such as quality and cooking methods, is also an important factor in considering specific marketing at the tactical level. For that reason, we look forward to conducting a future analysis that takes these differences into consideration.

\section{Acknowledgments}

The research in this paper was conducted as part of the Regional Strategy Project (16802899) of the Bio-oriented Technology Research Advancement Institution of the National Agriculture and Food Research Organization, along with a JSPS Grant-in-Aid for Scientific Research (16H02565). We express our gratitude to them. 


\section{References}

Aaker, D. A. (1991). Managing brand equity. New York, NY: Macmillan.

Alfnes, F. (2017). Selling only sustainable seafood: Attitudes toward public regulation and retailer policies. Marine Policy, 78, 74-79. https://doi.org/10.1016/j.marpol.2017.01.012

Al-Mazrooei, N., Chomo, G. V., \& Omezzine, A. (2003). Purchase behavior of consumers for seafood products. Agricultural and Marine Science, 8(1), 1-10.

Belsley, D. A., Kuh, E., \& Welsch, R. E. (1980). Regression diagnostics: Identifying influential data and sources of collinearity. New York: John Wiley.

Berry, R., \& Weaver, M. (2018). Exporting ecolabels: Is demand for certified sustainable products affecting international trade? Office of Industries Working Paper ID-052, U.S. International Trade Commission. Retrieved

from https://www.usitc.gov/publications/332/working_papers/exporting_ecolabels_final_with_cover_mjs_07171 8.pdf

Bose, S., \& Brown, N. (2000). A preliminary investigation of factors affecting seafood consumption behaviour in the inland and coastal regions of Victoria, Australia. International Journal of Consumer Studies, 24(4), 257-262. https://doi.org/10.1111/j.1470-6431.2000.00157.x

Claret, A., Guerrero, L., Gartzia, I., Garcia-Quiroga, M., \& Ginés, R. (2016). Does information affect consumer liking of farmed and wild fish? Aquaculture, 454, 157-162. https://doi.org/10.1016/j.aquaculture.2015.12.024

Craney, T. A., \& Surles, J. G. (2002). Model-dependent variance inflation factor cutoff values. Quality Engineering, 14(3), 391-403. https://doi.org/10.1081/QEN-120001878

Dellenbarger, L. E., Dillard, J., Schupp, A. R., Zapata, H. O., \& Young, B. T. (1992). Socioeconomic factors associated with at-home and away-from home catfish consumption in the United States. Agribusiness, $8(1)$, 35-46. Retrieved

from https://doi.org/10.1002/1520-6297(199201)8:1<35::AID-AGR2720080104>3.0.CO;2-V

El-Bassiouny, N. (2018). Images of Halal: A Traveler's Perspective on the Halal Market in Germany and Singapore. In Global Perspectives on Religious Tourism and Pilgrimage (pp. 142-158). IGI Global. https://doi.org/10.4018/978-1-5225-2796-1.ch009

FAO. (2016). Contributing to food security and nutrition for all. State of World Fisheries and Aquaculture. Rome: Food and Agriculture Organization, 2016.

Farmer, L. J., McConnell, J. M., \& Kilpatrick, D. J. (2000). Sensory characteristics of farmed and wild Atlantic salmon. Aquaculture, 187, 105-125. https://doi.org/10.1016/S0044-8486(99)00393-2

Fujimoto, N. (2015). [Status of exports in the agriculture and fishery in Hokkaido, and a data analysis of their effects on the regional economy], Japan Society for Information and Management, 35(2), 42-53.

Green-Petersen, D., Hyldig, G., Sveinsdóttir, K., Schelvis, R., \& Martinsdóttir, E. (2009). Consumer preference and description of salmon in four northern Atlantic countries and association with sensory characteristics. Journal of Aquatic Food Product Technology, 18(3), 223-244. https://doi.org/10.1080/10498850902747837

Herrmann, M. L., Mittelhammer, R. C., \& Lin, B.-H. (1993). Import demands for Norwegian farmed Atlantic salmon and wild pacific salmon in North America, Japan and the EC. Canadian Journal of Agricultural Economics/Revue Canadienne d'Agroeconomie, 111-125. https://doi.org/10.1111/j.1744-7976.1993.tb03736.x

Herrmann, R. O., Rauniyar, G. P., Hanson, G. D., \& Wang, G. (1994). Identifying frequent seafood purchasers in the Northeastern U.S. Agricultural and Resource Economics Review, 23(02), 226-235. https://doi.org/10.1017/S1068280500002343

Hibbeln, J. R. (2002). Seafood consumption, the DHA content of mothers' milk and prevalence rates of postpartum depression: A cross-national, ecological analysis. Journal of Affective Disorders, 69(1-3), 15-29. https://doi.org/10.1016/S0165-0327(01)00374-3.

Hiroi, O. (1998). Historical trends of salmon fisheries and stock conditions in Japan. North Pacific Anadromous Fish Commission Bulletin, 1, 23-27. $\quad$ Retrieved from http://www.npafc.org/new/publications/Bulletin/Bulletin\%20No.\%201/page\%2023-27(Hiroi).PDF 
Hocking, R. R., \& Pendleton, O. J. (1983). The regression dilemma. Communications in Statistics-Theory and Methods, 12(5), 497-527. Retrieved from https://doi.org/10.1080/03610928308828477

Ishida, Y., Ito, S., Kaeriyama, M., McKinnell, S., \& Nagasawa, K. (1993). Recent changes in age and size of chum salmon (Oncorhynchus keta) in the North Pacific Ocean and possible causes. Canadian Journal of Fisheries and Aquatic Sciences, 50(2), 290-295. https://doi.org/10.1139/f93-033

Jaffe, E., \& Nebenzahl, D. (2001). National image and competitive advantage: The theory and practice of country-of-origin effect. Copenhagen: Copenhagen Business School Press

Kaeriyama, M. (1998). Dynamics of chum salmon, Oncorhynchus keta, populations released from Hokkaido, Japan. North Pacific Anadromous Fish Commission Bulletin, 1, 90-102. Retrieved from http://www.npafc.org/new/publications/Bulletin/Bulletin\%20No.\%201/page\%2090-102(Kaeriyama).PDF

Kikuchi, M. (2013). Sake ga motarasu umi no megumi: sake no seikatsusi to kaiyoukigenbusshitu no yusou nitsuite [The Marine Blessings Which the Salmon Brings: Life History of Chum Salmon and Marine-Derived Nutrients]. Bulletin of the Society of Sea Water Science, 67(2), 101-103.

Kleppe, I., \& Mossberg, L. (2006). Company versus country branding: "Same, same but different". In F. Asche (Ed.), Primary industries facing global markets: The supply chains and markets for Norwegian food and forest products (pp. 217-246). Copenhagen Business School Press

Larsen, R., Eilertsen, K. E., \& Elvevoll, E. O. (2011). Health benefits of marine foods and ingredients. Biotechnology Advances, 29(5), 508-518. https://doi.org/10.1016/j.biotechadv.2011.05.017

Lee, D., Seo, S., Song, M. K., Lee, H. K., Park, S., \& Jin, Y. W. (2017). Factors associated with the risk perception and purchase decisions of Fukushima-related food in South Korea. PLoS ONE, 12(11), e0187655. https://doi.org/10.1371/journal.pone.0187655

Miyakoshi, Y., Nagata, M., Kitada, S., \& Kaeriyama, M. (2013). Historical and current hatchery programs and management of chum salmon in Hokkaido, Northern Japan. Reviews in Fisheries Science, 21(3-4), 469-479. https://doi.org/10.1080/10641262.2013.836446

Mohd Yasin, N., Nasser Noor, M., \& Mohamad, O. (2007). Does image of country-of-origin matter to brand equity? Journal of Product and Brand Management, 16(1), 38-48. https://doi.org/10.1108/10610420710731142

Muhammad, A., \& Jones, K. G. (2011). Source-based preferences and U.S. Salmon imports. Marine Resource Economics, 26(3), 191-209. https://doi.org/10.5950/0738-1360-26.3.191

Musaba, E. C., \& Namukwambi, M. (2011). Socio-economic determinants of consumer fish purchase in Windhoek, Namibia. African Journal of Agricultural Research, 6(6), 1483-1488. https://doi.org/10.5897/AJAR10.429

Nagata, M., Miyakoshi, Y., Urabe, H., Fujiwara, M., Sasaki, Y., Kasugai, K., ... Kaeriyama, M. (2012). An overview of salmon enhancement and the need to manage and monitor natural spawning in Hokkaido, Japan. Environmental Biology of Fishes, 94(1), 311-323. https://doi.org/10.1007/s10641-011-9882-3

Nayga, R. M., Jr., \& Capps, O., Jr. (1995). Factors affecting the probability of consuming fish and shellfish in the away from home and at home markets. Journal of Agricultural and Applied Economics, 27(01), 161-171. https://doi.org/10.1017/S1074070800019702

Rora, A. M. B., Monfort, M. C., \& Espe, M. (2004). Effects of country of origin on consumer preference of smoked salmon collected in a French hypermarket. Journal of Aquatic Food Product Technology, 13(1), 69-85. https://doi.org/10.1300/J030v13n01_07

Shimizu, I. (2007). Chugoku suisanbutu chousa wo tooshite mieta akisake yushutu to nihon no kadai [Chum salmon exports and issues in Japan found by survey of marine products in China]. Salmon Information, 1, 9-11.

Tanikawa, N. (2009). Nihon no suisangyo no genjo to kadai [Current status and issues of Japanese fishery industry]. The Bulletin of Chuo-Gakuin University-Man and Nature, 29, 79-89.

Yamao, M. (2013). Nihon no suisanbutsuboueki no kouzouhenka to higashiajia shokuhinsangyo kurasuta: hokai-do akisake yushutu wo jirei ni [Structural change of fisheries trade in Japan along with growth of food industries cluster in East Asia: a case study on Aki-sake (Oncorhynchus keta) in Hokkaido]. Agricultural and Fisheries Economics of Hiroshima University, 13, 1-18. 
Yao, G. (2011). Nihonsan shokuryouhin no taichugoku yushutu ni kansuru ichikousatu [A study on Japan's food exports to China]. Annals of the Institute for Research in Humanities and Social Sciences, 20, 45-60.

\section{Notes}

Note 1. Norwegian salmon that has a high fat content is called "fatty salmon," and is often consumed in Japan, while salmon that is wild-caught in Japan, is called "healthy salmon," and is exported to Europe and the United States via China (Kikuchi, 2013; Tanikawa, 2009).

Note 2. According to the Japanese Ministry of Agriculture, Forestry, and Fisheries' "The Fisheries and Aquaculture Production Statistics 2015," about 136,000 tons of salmon were caught in Japan, of which about 117,000 tons were caught in Hokkaido. In Japan, the majority of the salmon catch consists of Chum salmon. In this paper, "salmon" is used as a term to refer to commercially important salmon and trout such as the Chum salmon, Sockeye salmon, Pink salmon, Coho salmon, Atlantic Salmon, Rainbow trout, etc. "Salmon from Japan (Hokkaido)" and "Japanese salmon" refer to Chum salmon.

Note 3. Regulating supply and demand in these domestic markets and exporting with the aim of expanding to new markets, is not limited to salmon only, but is also applicable to Japan's exports of agricultural, forestry, and fishery products in general (Fujimoto, 2015).

Note 4. For "export strategies for agricultural, forestry and fishery products, differentiation of foods by country, and exports differentiated by commodity" we looked at foods and ingredients commonly used in Japanese cuisine and focused on countries and regions where markets for such foods develop. We are trying to promote exports by taking into consideration the needs of target countries / regions such as health and quality control.

Note 5. A food export value of 100 billion yen (seafood products / processed seafood products: 75 billion yen, agricultural and livestock products / processed agricultural and livestock products: 10 billion yen, and other processed foods: 15 billion yen) has been set as a target for Hokkaido in 2018.

Note 6. After hatching in rivers, Japanese salmon grows as they swim down to the sea and migrate to the middle of the North Pacific Ocean and the Bering Sea (Ishida et al., 1993). A few years later, they return to their home rivers where they hatched in order to lay eggs. Because salmon is caught as they return to their home rivers to give birth, there is a danger that overfishing will lead to a decreasing population. Therefore, in order to sustain salmon resources in Japan, a salmon hatchery program has become a government initiative. As a part of the program, people collect the eggs from caught parent salmon returning to their home rivers, artificially incubate and hatch the eggs, and release them into the rivers. Nearly all Japanese salmon is believed to be maintained by such hatchery programs (Hiroi, 1998; Kaeriyama, 1998).

Note 7. However, since Singaporean women in their 60s do not have a high internet-usage rate, at the time we obtained the online questionnaire data (from 600 people) in Singapore, we compared the proportion of respondents in this age group with their proportion in the overall population. We noticed a shortage of 20 people. Since the data was supplemented by adding data for women in their 50 s who were most similar to the women in their $60 \mathrm{~s}$, there is some bias among these groups. The ratio of actual respondents is about $28 \%$ greater for women in their 50 s than their actual population, and about 39\% less for women in their 60 s. However, as can be seen from the estimation results in Table 4, since gender and age did not significantly affect the analysis, we believe that such deviations barely had any influence on the analytical results.

Note 8. Answers such as "I do not know" or "Neither" were treated as missing values.

Note 9. Dellenbarger et al., (1992) specified socioeconomic factors that influence US catfish consumption both at home and away from home. Herrmann et al. (1994) analyzed factors that influence the purchasing frequency of seafood products both at home and out at restaurants in the Northeastern US. Nayga and Capps (1995) analyzed the effect of socioeconomic factors on the probability of consuming fish and shellfish in foreign and at home markets in the US. Bose and Brown (2000) comparatively analyzed and clarified the difference between the factors that affect consumers' behavior with respect to seafood products in inland and coastal regions in Victoria, Australia. In Al-Mazrooei et al. (2003) analyzed consumers in Oman. They made a distinction between differences in "purchase form such as whole fish, fillet and slice" and the "place of purchase such as on-shore market, supermarket and so on." In each case, they analyzed the primary factors leading to seafood products consumption. Musaba and Namukwambi (2011) analyzed the household characteristics of consumers in Windhoek, Namibia that influence the purchase of horse mackerel, hake, and snoek.

Note 10. Brand equity is the value of a brand name (Mohd Yasin et al., 2007). Brand equity is composed of four 
elements: brand awareness, brand loyalty, perceived quality, and brand associations (Aaker, 1991).

Note 11. Although there is no clear cutoff point to distinguish between a "high" and "low" VIF (Belsley et al., 1980), a VIF value of 5 or 10 is typically used as a reference value (Craney \& Surles, 2002; Hocking \& Pendelton, 1983).

Note 12. After the Fukushima Daiichi nuclear accident, South Korea imposed import restrictions on marine products from the eight prefectures of Aomori, Iwate, Fukushima, Miyagi, Ibaraki, Tochigi, Gunma, and Chiba.

Note 13. Based on the aggregated results from Q7, out of the 600 Koreans who responded to this survey, 98 (16\% of the total) responded that they thought Norwegian salmon was commonly "raised in captivity," 269 people (45\% of the total) thought that salmon was "wild-caught," and 233 people ( $39 \%$ of the total) answered that they "were not sure."

\section{Copyrights}

Copyright for this article is retained by the author(s), with first publication rights granted to the journal.

This is an open-access article distributed under the terms and conditions of the Creative Commons Attribution license (http://creativecommons.org/licenses/by/4.0/). 